\title{
High Cumulative Doses of Pegylated Liposomal Doxorubicin Are Not Associated with Cardiac Toxicity in Patients with Gynecologic Malignancies
}

\author{
Joshua P. Kesterson Kunle Odunsi Shashikant Lele \\ Division of Gynecologic Oncology, Roswell Park Cancer Institute, Buffalo, N.Y., USA
}

\section{Key Words}

Pegylated liposomal doxorubicin · Cardiotoxicity

\begin{abstract}
Purpose: The purpose of this study was to determine the cardiac safety of pegylated liposomal doxorubicin (PLD) in patients receiving high cumulative doses of PLD. Materials and Methods: A retrospective chart review of women with gynecologic malignancies treated at Roswell Park Cancer Institute from 2002 through 2007 who received cumulative doses of PLD $\geq 400 \mathrm{mg} / \mathrm{m}^{2}$ was performed. Results: Fortytwo of 116 patients met the inclusion criteria. The mean age at initiation of PLD therapy was 63 years. The mean cumulative dose of PLD was $663.9 \mathrm{mg} / \mathrm{m}^{2}$ (range $400-1,524 \mathrm{mg} / \mathrm{m}^{2}$ ). The mean cumulative number of cycles of PLD given was 9.8 (range 5-25). Multigated acquisition (MUGA) scans were obtained in $93 \%$ (39/42) of patients prior to or immediately following their first dose of PLD. The mean baseline ejection fraction was 63\% (range 49-76\%). Follow-up MUGA scans were performed on 7 patients (17\%). Two of these patients had a decrease in their ejection fraction, but of only 3 and $1 \%$. The remaining 5 patients who had follow-up MUGA scans had an average increase in their left ventricular ejection fraction of $4 \%$ (range 1-9\%). No patients developed clinical evidence of congestive heart failure while being treated
\end{abstract}

with PLD. There were no treatment interruptions or discontinuations due to cardiac toxicity. Conclusion: Cumulative doses of PLD $\geq 400 \mathrm{mg} / \mathrm{m}^{2}$ are not associated with clinically evident cardiac toxicity in gynecologic oncology patients.

Copyright $\odot 2010$ S. Karger AG, Basel

\section{Introduction}

Doxorubicin in its unaltered form has proven anticancer activity, however its clinical use is limited by its cardiotoxicity. Over one quarter of patients treated with up to $550 \mathrm{mg} / \mathrm{m}^{2}$ will experience doxorubicin-related congestive heart failure (CHF) [1]. In order to minimize doxorubicin's adverse effects, investigators initially explored means by which to optimize dosing in order to minimize side effects $[2,3]$, however, more recently new formulations of the drug have been developed. Pegylated liposomal doxorubicin (PLD) is a unique formulation in which a doxorubicin-containing liposome is surrounded by a polyethylene glycol layer. This formulation protects it from being taken up by mononuclear phagocyte cells,

This work was presented as a poster at the Society of Gynecologic Oncologists' 40th Annual Meeting (San Antonio, Tex., USA).

\section{KARGER}

Fax +41613061234 E-Mail karger@karger.ch www.karger.com
(C) 2010 S. Karger AG, Basel

$0009-3157 / 10 / 0562-0108 \$ 26.00 / 0$

Accessible online at:

www.karger.com/che
Shashikant Lele, MD

Division of Gynecologic Oncology, Roswell Park Cancer Institute

Elm and Carlton Streets

Buffalo, NY 14263 (USA)

Tel. +1 716845 5776, Fax +1 716845 7608, E-Mail shashi.lele@ roswellpark.org 
resulting in a prolonged plasma half-life. Liposomal encapsulation allows for decreased accumulation within the heart and greater accumulation within tumor sites [4].

PLD is an effective and tolerable agent in the treatment of recurrent and refractory ovarian carcinoma [5-9]. PLD has been shown to have a significantly reduced cardiac toxicity with similar efficacy when compared to doxorubicin in patients with metastatic breast cancer [10]. A few, small studies have evaluated the cardiac safety of high cumulative doses of PLD in gynecologic oncology patients [11-13]. The purpose of this study was to determine the cardiac safety of PLD in gynecologic oncology patients receiving high cumulative doses of PLD.

\section{Methods}

After obtaining approval from the Roswell Park Cancer Institute institutional review board, a retrospective chart review of women with gynecologic malignancies treated at Roswell Park Cancer Institute from 2002 to 2007 who received $\geq 400 \mathrm{mg} / \mathrm{m}^{2}$ of PLD was performed. Data collected included age, height, weight, medical comorbidities (i.e. diabetes mellitus and hypertension), cumulative dose and number of courses of PLD received, left ventricular ejection fraction as determined by multigated acquisition (MUGA) scans and at baseline and during follow up (if available), and any signs and symptoms of CHF. MUGA scans were considered 'baseline' if they were obtained prior to the initiation of PLD chemotherapy or immediately following the first course. BMI was calculated as: body weight $(\mathrm{kg}) /$ height $(\mathrm{m})^{2}$. BMI was categorized as follows: $<18.5$ underweight; $18.5-24.9$ normal; $25-29.9$ overweight, and $\geq 30$ obese [14].

PLD was administered at initial doses of 30 or $40 \mathrm{mg} / \mathrm{m}^{2}$. Therapy was repeated every 4 weeks. Adjustments for toxicity consisted of either dose reduction or treatment delay.

\section{Results}

Forty-two of 116 patients met the inclusion criteria. The mean age at initiation of PLD therapy was 63 years. Thirty-six patients were being treated for either ovarian, primary peritoneal or fallopian tube carcinoma. Four patients had an endometrial primary cancer and 1 patient each was being treated for cervical and vulvar cancer. Fifty-seven percent $(24 / 42)$ of patients had a diagnosis of hypertension and $14 \%(6 / 42)$ of patients were diabetic, including 4 patients who were both diabetic and hypertensive. BMI was able to be calculated for 41 patients. The average BMI was 28.6 (range 17.4-51.2). One patient was underweight (2.4\%), 16 patients were normal weight (39\%), 8 patients were overweight (20\%) and 16 patients
Table 1. Characteristics of study patients and summary of MUGA scan results

\begin{tabular}{|c|c|}
\hline Variables & Patients (\%) \\
\hline Total patients & 42 \\
\hline Age, years & 63 \\
\hline \multicolumn{2}{|l|}{ Tumor site } \\
\hline Ovary & $25(60)$ \\
\hline Primary peritoneal & $8(19)$ \\
\hline Endometrial & $4(10)$ \\
\hline Fallopian tube & $3(7)$ \\
\hline Cervix & $1(4)$ \\
\hline Vulva & $1(4)$ \\
\hline Hypertensive & $24(57)$ \\
\hline Diabetic & $6(14)$ \\
\hline \multicolumn{2}{|l|}{ BMI } \\
\hline Mean & 28.6 \\
\hline Range & $17.4-51.2$ \\
\hline \multicolumn{2}{|l|}{ Cumulative dose of PLD, $\mathrm{mg} / \mathrm{m}^{2}$} \\
\hline Mean & 664 \\
\hline Range & $400-1,524$ \\
\hline \multicolumn{2}{|l|}{ Number of PLD cycles } \\
\hline Mean & 9.5 \\
\hline Range & $5-25$ \\
\hline Number of patients with baseline MUGA scan & $41(98)$ \\
\hline \multicolumn{2}{|l|}{ Baseline MUGA scan ejection fraction, $\%$} \\
\hline Mean & 63 \\
\hline Range & $49-76$ \\
\hline Patients with follow-up MUGA scan & $7(17)$ \\
\hline \multicolumn{2}{|l|}{ Change in MUGA ejection fraction at follow-up, \% } \\
\hline Mean & +2.3 \\
\hline Range & -3 to +9 \\
\hline Patients with evidence of CHF while on PLD & $0(0)$ \\
\hline Patients who discontinued PLD for CHF & $0(0)$ \\
\hline
\end{tabular}

(39\%) were obese. The mean cumulative dose of PLD was $663.9 \mathrm{mg} / \mathrm{m}^{2}$ (range $400-1,524 \mathrm{mg} / \mathrm{m}^{2}$ ). The mean cumulative number of cycles of PLD given was 9.5 (range 5-25). No patients were previously treated with doxorubicin. Patient characteristics are shown in table 1.

MUGA scans were obtained in 98\% (41/42) of patients prior to or immediately following their first dose of PLD. The mean baseline ejection fraction was 63\% (range 4976). Only 1 patient had an abnormal left ventricular ejection fraction (LVEF; 49\%) at the initiation of therapy (normal $\geq 50 \%$ ). However, at a follow-up MUGA scan after her second course of PLD this increased to 55\%. Follow-up MUGA scans were performed on 7 patients (17\%). Mean change was $+2.3 \%$ with a range of $-3 \%$ to $+9 \%$. Two patients had a decrease in their ejection fraction, but of only 3 and $1 \%$, which was not clinically significant. In the 
patient who showed an initial 3\% drop in her LVEF (from $75 \%$ at baseline to $72 \%$ after her eighth cycle), it was ultimately $77 \%$ after completion of her 14 th cycle of PLD. The remaining 5 patients who had follow-up MUGA scans had an average increase in their LVEF of 4\% (range 1$9 \%)$.

No patients developed clinical evidence of CHF while being treated with PLD. There were no treatment interruptions or discontinuations due to cardiac toxicity.

\section{Discussion}

Doxorubicin is an effective anti-tumor agent, however its use is limited by its associated cardiotoxicity. In a recent meta-analysis of three phase III trials involving 630 patients treated with doxorubicin, Swain et al. [1] reported that the cumulative risks of developing doxorubicin-induced $\mathrm{CHF}$ were $5 \%$ at a cumulative dose of 400 $\mathrm{mg} / \mathrm{m}^{2}, 26 \%$ at $550 \mathrm{mg} / \mathrm{m}^{2}$ and $48 \%$ at $700 \mathrm{mg} / \mathrm{m}^{2}$. One strategy for reducing doxorubicin's cardiotoxicity is to coat the drug in a liposomal capsule. PLD is a unique formulation in which a doxorubicin-containing liposome is surrounded by a polyethylene glycol layer. PLD has proven activity in the treatment of recurrent and refractory epithelial ovarian carcinoma $[5,6,9,15]$.

Few studies have evaluated the cardiac safety of high cumulative doses of PLD in gynecologic oncology patients. Uyar et al. [13] reported on 22 patients with gynecologic malignancies who received a median of $8 \mathrm{cy}-$ cles and a median cumulative dose of $483 \mathrm{mg} / \mathrm{m}^{2}$ of PLD. There were no dose reductions secondary to cardiac dysfunction. Of the 7 patients who received serial MUGA scans, none had a decrease in LVEF to less than $50 \%$, and only 1 had a decrease in LVEF of $\geq 10 \%$ compared to baseline. That patient had no clinical evidence of cardiac dysfunction and continued PLD therapy. In 2007, Andreopoulou et al. [11] reported their experience treating patients with recurrent epithelial ovarian cancer with PLD. Sixteen patients were treated with PLD for more than 1 year. PLD was primarily given in combination with another agent (carboplatin in 5 patients and topotecan in 9 patients). Eleven patients had a MUGA scan before and after PLD therapy. No patient had a $>9 \%$ decline in LVEF after receiving PLD except 1 patient who, 10 months after discontinuation of PLD, developed cardiogenic shock during an episode of neutropenic sepsis with a LVEF of $20 \%$ which subsequently recovered to $45 \%$. Safra et al. [12] performed a retrospective analysis of 42 patients who received more than
$500 \mathrm{mg} / \mathrm{m}^{2}$ of PLD, including 20 patients with ovarian cancer. With a median dose of PLD of $660 \mathrm{mg} / \mathrm{m}^{2}$, none of the 42 patients had clinical CHF. Forty-one of $42 \mathrm{pa}-$ tients had MUGA scans and only 5 had a drop in LVEF of $\geq 10 \%$, three of whom had received prior doxorubicin.

In our study of gynecologic oncology patients, a majority of whom are overweight and have medical comorbidities, receiving a mean cumulative dose of 663.9 $\mathrm{mg} / \mathrm{m}^{2}$ of PLD, no patients developed clinical evidence of CHF while receiving PLD. These results are consistent with prior PLD studies showing an improved cardiac safety profile of PLD compared to doxorubicin [10, $12,13,16]$. Between 26 and $48 \%$ of patients receiving the same cumulative dose of doxorubicin as PLD received in our study would be expected to have anthracyclineinduced CHF. Secondary to doxorubicin's cardiotoxicity, Schwartz et al. [17] formulated criteria for monitoring LVEF and discontinuing doxorubicin. Their recommended guidelines included serial assessment of LVEF as a means to reduce the incidence and severity of CHF and to identify patients who can safely tolerate high cumulative doses of doxorubicin. Extrapolating from the doxorubicin data, our institution routinely assesses LVEF via a MUGA scan prior to the initiation of PLD. In our study, almost all $(98 \%, 41 / 42)$ patients initiated PLD therapy with a normal LVEF. There were no clinically evident cases of CHF or treatment modifications based on followup MUGA scans, supporting a lack of associated cardiac toxicity in this patient population.

The cardiac safety profile of high cumulative doses of PLD in gynecologic oncology patients demonstrated in this and other studies shows the lack of usefulness of serial LVEF assessment in the absence of clinical indications [11-13]. In gynecologic malignancies, PLD is administered mainly to patients with recurrent ovarian cancer, where the primary goal is symptom relief and improvement in quality of life. In patients whose tumors are responding to PLD, it does not appear that management would be altered based on the cumulative dose of PLD the patient has received.

Based on our study, high cumulative doses of PLD do not adversely impact cardiac function. Those patients who have received prior doxorubicin therapy, however, need careful observation and monitoring secondary to the significant cardiotoxicity risk with high cumulative doses of doxorubicin. Larger studies are needed to confirm these results as well as future investigations into the benefit of monitoring for cardiac dysfunction via assessment of LVEF in those patients treated with PLD. 
Future studies should also focus on the role of biomarkers, such as troponin and natriuretic peptides, in assessing early signs of cardiac dysfunction in patients receiving chemotherapy with the potential for cardiac toxicity [18-20].

\section{Acknowledgment}

The authors would like to thank Joanne Masterson for her time and effort in the preparation of the manuscript.

\section{References}

1 Swain SM, Whaley FS, Ewer MS: Congestive heart failure in patients treated with doxorubicin: a retrospective analysis of three trials. Cancer 2003;97:2869-2879.

2 al-Gharably NM, Osman AM, al-Shabanah OA, al-Bekairi AM, al-Harbi MM: Potentiation of doxorubicin cytotoxicity by the calcium channel blocker verapamil in Ehrlich ascites cells. Chemotherapy 1993;39:410415.

3 al-Shabanah OA, Osman AM, al-Harbi MM, al-Gharably NM, al-Bekairi AM: Enhancement of doxorubicin-induced cytotoxicity by hyperthermia in Ehrlich ascites cells. Chemotherapy 1994;40:188-194.

4 Waterhouse DN, Tardi PG, Mayer LD, Bally MB: A comparison of liposomal formulations of doxorubicin with drug administered in free form: changing toxicity profiles. Drug Saf 2001;24:903-920.

5 Campos SM, Penson RT, Mays AR, Berkowitz RS, Fuller AF, Goodman A, Matulonis UA, Muzikansky A, Seiden MV: The clinical utility of liposomal doxorubicin in recurrent ovarian cancer. Gynecol Oncol 2001;81:206212.

-6 Gordon AN, Granai CO, Rose PG, Hainsworth J, Lopez A, Weissman C, Rosales R, Sharpington T: Phase II study of liposomal doxorubicin in platinum- and paclitaxel-refractory epithelial ovarian cancer. J Clin Oncol 2000;18:3093-3100.

7 Muggia FM, Hainsworth JD, Jeffers S, Miller P, Groshen S, Tan M, Roman L, Uziely B, Muderspach L, Garcia A, Burnett A, Greco FA, Morrow CP, Paradiso LJ, Liang LJ: Phase II study of liposomal doxorubicin in refractory ovarian cancer: antitumor activity and toxicity modification by liposomal encapsulation. J Clin Oncol 1997;15:987-993.
8 Rose PG, Maxson JH, Fusco N, Mossbruger $\mathrm{K}$, Rodriguez M: Liposomal doxorubicin in ovarian, peritoneal, and tubal carcinoma: a retrospective comparative study of singleagent dosages. Gynecol Oncol 2001;82:323328.

-9 Thigpen JT, Aghajanian CA, Alberts DS, Campos SM, Gordon AN, Markman M, McMeekin DS, Monk BJ, Rose PG: Role of pegylated liposomal doxorubicin in ovarian cancer. Gynecol Oncol 2005;96:10-18.

10 O’Brien ME, Wigler N, Inbar M, Rosso R, Grischke E, Santoro A, Catane R, Kieback DG, Tomczak P, Ackland SP, Orlandi F, Mellars L, Alland L, Tendler C: Reduced cardiotoxicity and comparable efficacy in a phase III trial of pegylated liposomal doxorubicin $\mathrm{HCl}$ (CAELYX/Doxil) versus conventional doxorubicin for first-line treatment of metastatic breast cancer. Ann Oncol 2004;15: 440-449.

11 Andreopoulou E, Gaiotti D, Kim E, Downey A, Mirchandani D, Hamilton A, Jacobs A, Curtin J, Muggia F: Pegylated liposomal doxorubicin HCL (PLD; Caelyx/Doxil): experience with long-term maintenance in responding patients with recurrent epithelial ovarian cancer. Ann Oncol 2007;18:716721.

12 Safra T, Muggia F, Jeffers S, Tsao-Wei DD, Groshen S, Lyass O, Henderson R, Berry G, Gabizon A: Pegylated liposomal doxorubicin (doxil): reduced clinical cardiotoxicity in patients reaching or exceeding cumulative doses of $500 \mathrm{mg} / \mathrm{m}^{2}$. Ann Oncol 2000;11: 1029-1033.
13 Uyar D, Kulp B, Peterson G, Zanotti K, Markman M, Belinson J: Cardiac safety profile of prolonged ( $\geq 6$ cycles) pegylated liposomal doxorubicin administration in patients with gynecologic malignancies. Gynecol Oncol 2004;94:147-151.

14 Obesity: preventing and managing the global epidemic. Report of a WHO consultation. World Health Organ Tech Rep Ser 2000;894: i-xii, 1-253.

15 Gordon AN, Fleagle JT, Guthrie D, Parkin DE, Gore ME, Lacave AJ: Recurrent epithelial ovarian carcinoma: a randomized phase III study of pegylated liposomal doxorubicin versus topotecan. J Clin Oncol 2001;19:33123322.

16 Theodoulou M, Hudis C: Cardiac profiles of liposomal anthracyclines: greater cardiac safety versus conventional doxorubicin? Cancer 2004;100:2052-2063.

17 Schwartz RG, McKenzie WB, Alexander J, Sager P, D'Souza A, Manatunga A, Schwartz PE, Berger HJ, Setaro J, Surkin L, et al: Congestive heart failure and left ventricular dysfunction complicating doxorubicin therapy. Seven-year experience using serial radionuclide angiocardiography. Am J Med 1987;82: 1109-1118

18 Gianni L, Herman EH, Lipshultz SE, Minotti G, Sarvazyan N, Sawyer DB: Anthracycline cardiotoxicity: from bench to bedside. J Clin Oncol 2008;26:3777-3784.

19 Ng R, Better N, Green MD: Anticancer agents and cardiotoxicity. Semin Oncol 2006;33:2-14.

20 Urbanova D, Urban L, Danova K, Simkova I: Natriuretic peptides: biochemical markers of anthracycline cardiac toxicity? Oncol Res 2008; 17:51-58. 